energy from a single quantum for the transfer of an electron to the level of reduction of coenzyme, and that of the biochemist who prefers the simpler view that one electron is transferred per quantum. Kamen's article on the possible role of cytochromes is an excellent example of the biologist stating his view to the physical chemist. Such conferences as that at Gatlinburg fulfil a real need in stimulating discussion between workers from different scientific disciplines.

The general reader will find the book primarily of use as a source book of references. Unfortunately, from his point of view, it was not possible to include much of the work concerning the carbon metabolism of photosynthesis. The conference was intentionally limited to a detailed discussion of a few topics rather than attempting a complete survey.

\section{P. WhittinghaM}

\section{NUCLEAR CHEMISTRY}

La Chimie Nucléaire et ses Applications

Par M. Haïssinsky. Pp. vi +652 . (Paris : Masson et Cie., 1957.) Broché, 5,000 francs; Cartonné toile, 5,600 francs.

$\mathbf{T}$ is fitting that the country in which radioactivity 1 was first discovered should be the first to publish a major text-book which surveys virtually all the sciences and techniques in which radioactivity has come to play a part.

The first chapter, "La chimie nucléaire-ses grandes étapes", is an admirable account of the early work on radioactivity. There is the story of Becquerel's mystification over the strange trick of Nature that gave some uranium compounds both radioactive and strong fluorescent properties, and the way the Curies solved it in discovering the other radioactive elements : "la lucidité et la sûreté avec lesquelles ils ont advancé vers le but qu'ils s'étaient proposé, sur une voie jamais encore tracée". In this chapter there are included interesting pictures showing the blackening of the photographic plate which Becquerel first observed, and facsimiles of pages from the note-books of the Curies and of Rutherford.

Following this beginning, there are five chapters on the physical basis of radioactivity and three chapters on the radioactive elements, including the transuranium elements. The transuranium elements are divided into the 'uranides' (multivalent elements) and the 'curides' (mainly trivalent elements), but I feel this subdivision leads to words that sound badly in an English pronunciation, and it is not a clearly defined subdivision. These chapters lead up to the applications of radioactivity in geology and astrophysics, and there are good accounts of such problems as the determination of the age of the Earth. Following this, there comes a section comprising almost a third of the whole book, devoted to radiation chemistry. Separate chapters are given to the effects of radiation on gases, water and aqueous solutions, organic systems, solids and fluorescent systems. There is also a valuable chapter on the chemical effects associated with nuclear transformations. The last part of the book describes radioactive tracers and their applications and includes chapters on electrochemistry, reaction mechanisms, anølysis, biochemistry and industrial processes.
A criticism of the book is that it attempts to make into one subject something that is really dispersed over a great many quite separate subjects. Nuclear chemistry in Britain, and in the United States, is normally regarded as a rather small subject restricted to a study of atomic nuclei and their reactions. Of this there is comparatively little in the book and it is dis. cussed rather briefly. The chapters on radiation chemistry, on the other hand, constitute a major review suitable for a research student who would be interested neither in the nuclear problems, nor in the behaviour of radioactive tracers. The book is a notable attempt to bring order into a confused situation, but in practice, if the book were to be translated into English, it is not clear what type of student in Britzin would find it useful.

The references are very full and up to date throughout the whole book, and in this respect the author has done a great service in assembling them. Minor criticisms are that there is no collated information such as a complete table of isotopes, or of crosssections, and that the author index often lists several different people under one name by being restricted to one initial. There are also numerous typographical errors, particularly in such details as the alignment of subscripts, but errors in the actual text are very few for a book covering such a wide field.

G. N. Walton

\section{PAPER-MAKING}

\section{Fundamentals of the Beating Process}

The Theory of the Development in Pulps of Papermaking Characteristics by Mechanical Treatment. By H. W. Emerton. Pp. xvi 198 (145 figures). (Kenley : British Paper and Board Industry Research Association, 1957.) $42 s$.

WHIS volume refers to the mechanical treatment undergone by pulp fibres in preparation for paper making, and its author is principal research officer (physics) of the British Paper and Board Industry Research Association. It is addressed primarily to the paper-mill chemist, but it can also be read with much profit by all interested in fibre and cellulose science. A special feature is the numerous light- and electron-micrographs illustrating techniques of which Emerton is a recognized leading exponent.

Part I deals with the chemistry and structure of cellulose fibres. Part II covers the theory of beating (the most important and controversial chapter of the book), factors affecting the beating behaviour of pulp, methods for the determination of the progress of beating, and the effect of beating on the properties of paper. It is concluded that beating to produce strength increases the bonded area between fibres by making them plastic, so that they deform by surface tension during drying. Deformation provides the opportunity for bonding, the extent of which will depend on the degree of dispersion of the cellulose and other polysaccharides of the surface layer.

It will be seen that the general treatment is on a relatively elementary scientific plane, the purely practical mill aspects of the subject being deliberately excluded. There are a full index, and a liberal bibliography for the benefit of scientific readers outside the industry. 